\title{
Processos de Comunicação em Cooperações Tecnológicas Universidade-Empresa: Estudos de Caso em Universidades Federais do Paraná
}

\section{Technological Processes of Communication in Cooperation University-Enterprise: Studies of Cases in Paraná Federal Universities}

\author{
Érika Mayumi Kato Cruz * \\ Mestre em Administração pela UFPR. \\ Professora da UNIESP, Presidente Prudente/SP, Brasil. \\ Andréa Paula Segatto \\ Doutora em Administração pela USP. \\ Professora do DAGA/UFPR, Curitiba/PR, Brasil.
}

* Endereço: Érika Mayumi Kato Cruz

Rua Francisco Machado de Campos, 77, Vila Nova, Presidente Prudente/SP, 19010-300. E-mail: erikinhakato@yahoo.com.br

Copyright (C) 2009 RAC. Todos os direitos, inclusive de tradução, são reservados. É permitido citar parte de artigos sem autorização prévia desde que seja identificada a fonte. 


\section{RESUMO}

As cooperações tecnológicas universidade-empresa representam arranjos de interesse crescente. A natureza distinta dos parceiros torna relevante uma complementaridade de interesses. Neste contexto, é fundamental trocas de informações precisas entre empresa e academia. O estudo objetivou caracterizar os processos de comunicação em cooperações tecnológicas universidade-empresa ao longo das fases de desenvolvimento da cooperação. Consiste em pesquisa qualitativa de natureza descritiva-exploratória, que fez uso de estudos de casos múltiplos. Os casos de cooperação estudados envolveram acordos feitos entre empresas e universidades federais do Paraná; os resultados das análises apontam trocas de mensagens específicas a cada fase do processo cooperativo e variedade de meios de comunicação adequados às mensagens. Apesar da inserção de meios mais modernos de comunicação, nota-se ainda o uso de meios convencionais. Destaca-se também a participação das estruturas de interface, fato característico do tipo de acordo estudado. As cooperações abordadas trouxeram benefícios para ambas as partes; no entanto foi possível a identificação de ruídos ao longo do processo.

Palavras-chave: cooperação tecnológica universidade-empresa; fases de desenvolvimento da cooperação; comunicação; processos de comunicação.

\section{ABSTRACT}

The technological cooperation university-industry constitutes arrangements with increasing interest. The distinctive nature of the parties involved parts makes it important for one to complement the interests of the other. Therefore, it is a fundamental aspect that there should be a precise exchange of information between the company and academia. In this context, studying the communication process is highly relevant in order to achieve a satisfactory relationship between the partners involved in the agreement. The aim of this study is to characterize the communication process in a technological cooperation between university-industry during the phases of cooperation development. The study consists of qualitative research of a descriptive-exploratory nature, which made use of multiple studies. The cooperation cases under study involved agreements between companies and the Federal Universities of Paraná, and the results of the analyses show exchanges of specific messages for each phase of the cooperative process and a variety of medias that were adapted to the messages. Although the insertion of more modern ways of communication can be seen, conventional means of communication are still in use. The interface structures are highlighted, a characteristic feature of the type of agreement under study. The cooperations involved in the study resulted in benefits for both parties; nevertheless, there were sings of interference throughout the process.

Key words: technological cooperation university-industry; cooperative development phases; communication; communication processes. 


\section{INTRODUÇÃO}

No âmbito do atual contexto econômico e social, a cooperação tecnológica entre universidade e empresa constitui um arranjo de interesse crescente e se encontra intimamente ligada ao desenvolvimento tecnológico exigido pela economia moderna (Cunha \& Fischman, 2003; Stal, 1998).

Conforme afirmam Guimarães e Plonski (2004), em processo de cooperação é fundamental estabelecer-se um fluxo de conhecimento entre a academia e o setor produtivo, de forma a possibilitar uma transferência bem-sucedida de tecnologia e, consequentemente, maior desenvolvimento tecnológico destes agentes. No entanto, o aparecimento de barreiras na condução deste processo acaba, muitas vezes, comprometendo, e até mesmo impossibilitando, o relacionamento entre a universidade e a empresa, sendo a ausência da comunicação um destes obstáculos (Cunha \& Fischman, 2003; Porto, 2002; Segatto, 1996; Segatto-Mendes \& Sbragia, 2002).

No cenário contemporâneo, a capacidade de processamento de informações apresenta-se como fonte fundamental de riqueza, agregação de valor, produtividade e crescimento econômico das organizações (Castells, 2003). Dessa forma, as organizações podem ser vistas como sistemas de processamento de informações, ou seja, como canais por meio dos quais as informações fluem (Hall, 2004; Putnam, Philips, \& Chapman, 2004). Diante do exposto, a comunicação representa um aspecto organizacional importante, para que se tenha uma acurada e adequada transmissão de informações e conhecimento.

Logo, o fornecimento de informações precisas por meio da comunicação torna-se essencial para que o conteúdo desta última atinja todos os receptores que dela necessitam (Hall, 2004). Neste contexto, em processo de cooperação universidade-empresa, a comunicação torna-se um aspecto relevante, podendo ser vista como um dos fatores que influenciam a busca de uma relação satisfatória entre os agentes envolvidos no acordo cooperativo.

Diante do exposto, o presente estudo buscou caracterizar os processos de comunicação em cooperações tecnológicas universidade-empresa, ao longo das fases de desenvolvimento da cooperação, analisando, para este fim, os diversos aspectos que integram os processos de comunicação identificados: emissores, receptores, mensagens, meios de comunicação, ruídos e retroalimentação.

\section{COOPERAÇÃO TECNOLÓGICA UNIVERSIDADE-EMPRESA}

No decorrer dos anos, a interação da academia com a indústria tem assumido espaço cada vez mais expressivo nas discussões dos pesquisadores (Porto, 2004). Com a elevada competitividade mundial e a globalização dos mercados, as empresas ampliaram os recursos externos de Pesquisa e Desenvolvimento [P\&D], tornando-se importante fonte alternativa de recursos; já as universidades, por sua vez, passaram a ser vistas como fonte significativa de tecnologia (Porto, 2004; Vasconcellos, Waack, \& Vasconcellos, 1997).

De acordo com Porto, Prado e Plonski (2003), as cooperações tecnológicas universidade-empresa representam uma necessidade dos agentes, visando garantir o futuro de ambos, bem como potenciar conhecimento e capacitações crescentes, e cada vez mais complexos.

Para Plonski (1999), geralmente entende-se por empresa uma pessoa jurídica, podendo também constituir-se uma pessoa física ou empresa informal. Quanto à universidade, o autor ressalta a existência de uma variedade de entidades de ensino e/ou pesquisa, aí incluindo qualquer instituição de ensino superior, instituições de pesquisa, fundações de direito privado conveniadas com alguma instituição de ensino superior, empresas juniores e até mesmo docentes que realizam consultorias individuais. Destaca-se, assim, o conceito apresentado por Plonski (1995, p. 65), que define cooperação tecnológica universidade-empresa como 
um modelo de arranjo interinstitucional entre organizações de natureza fundamentalmente distinta, que podem ter finalidades diferentes e adotar formatos bastante diversos. Incluem-se nesse conceito desde interações tênues e pouco comprometedoras, como o oferecimento de estágios profissionalizantes, até vinculações intensas e extensas como os grandes programas de pesquisa cooperativa em que chega a ocorrer repartição dos réditos resultantes da comercialização de seus resultados.

De forma complementar, Segatto-Mendes (2001) afirma que, uma vez que a relação de cooperação entre universidade e empresa envolve grupos distintos de pessoas provenientes de condições e pesquisas diversas, não há um consenso no que tange aos tipos de relações que se podem estabelecer. Assim, como visto em Lima e Teixeira (2001), a viabilidade de um acordo de cooperação pode estar atrelada a diversas formas de interações que, segundo Bonaccorsi e Piccaluga (1994 como citado em Segatto, 1996, pp. 31-32) podem variar conforme o grau crescente de comprometimento de recursos, duração do relacionamento e formalização dos acordos.

Conforme Plonski (1999), essa variedade de interações que se podem estabelecer entre universidade e empresa ocorre, principalmente, em função de três fatores, a saber: (1) o conteúdo transacional: envolve o alcance dos objetivos inerentes à cooperação, ou seja, o tipo de projeto a ser desenvolvido em conjunto; (2) a forma: estabelece se o acordo de cooperação é bilateral (uma empresa e uma universidade) ou multilateral (mais de uma empresa e/ou mais de uma universidade), se ocorre em uma mesma microrregião ou se constitui uma cooperação internacional, se é de curto ou de longo prazo (projetos concebidos à medida que a cooperação evolui), se envolve ou não alguma troca de recursos financeiros e se utiliza ou não recursos externos; por fim, (3) as estruturas de interface: mecanismos intermediários que visam promover e facilitar a relação de cooperação.

Dentre os diversos modelos de processos de cooperação da universidade com a empresa, destacamse os apresentados por Sbragia (1994 como citado em Segatto, 1996, p. 11) e Bonaccorsi e Piccaluga (1994 como citado em Segatto, 1996, p. 13). No modelo apresentado por Sbragia (1994 como citado em Segatto, 1996, p. 11), o processo de cooperação universidade-empresa envolve três estágios, a saber: disposição de cooperar, intercâmbio de informações e cooperação efetiva. No primeiro estágio, tem-se o interesse dos parceiros no que diz respeito à vontade de estabelecer a cooperação; no segundo, as partes começam a trocar informações na busca de um consenso para o estabelecimento do acordo cooperativo; por fim, tem-se a cooperação efetiva, na qual a busca por informações se torna constante e há uma conscientização dos envolvidos, no que concerne aos benefícios que irão conseguir com a cooperação (Segatto, 1996).

Com a realização de estudos sobre cooperação tecnológica universidade-empresa, Bonaccorsi e Piccaluga (1994 como citado em Segatto, 1996, p. 13) também apresentam uma estruturação teórica do processo. Segundo os autores, um processo de cooperação entre a academia e o setor produtivo contempla blocos como motivações das firmas, estrutura e procedimentos das relações interorganizacionais, processo de transferência do conhecimento, expectativas, desempenho, medidas de objetivos, geração de novos objetivos e resultados das relações interorganizacionais.

De forma complementar, Ring e Van de Ven (1994), buscando compreender o ciclo de vida das interações interorganizacionais, apresentam um modelo de desenvolvimento destas relações, que compreende as etapas de negociação, de comprometimento e de execução. Segundo os autores, a concepção do modelo pode ser representada graficamente por um ciclo de ações não linear, de forma a garantir a manutenção dos processos envolvidos; assim, é possível entender-se a interação estudada, sem que o referido processo atinja o seu fim. Assim, na medida em que uma cooperação tecnológica pode ser considerada relação interorganizacional cooperativa, o referido modelo se aplica também aos processos de cooperação universidade-empresa.

Diante do exposto, uma mesclagem dos modelos apresentados acima permite a montagem da seguinte estrutura, com o intuito de estudar as cooperações tecnológicas universidade-empresa (Figura 1). 
Figura 1: Processo de Cooperação Universidade-Empresa

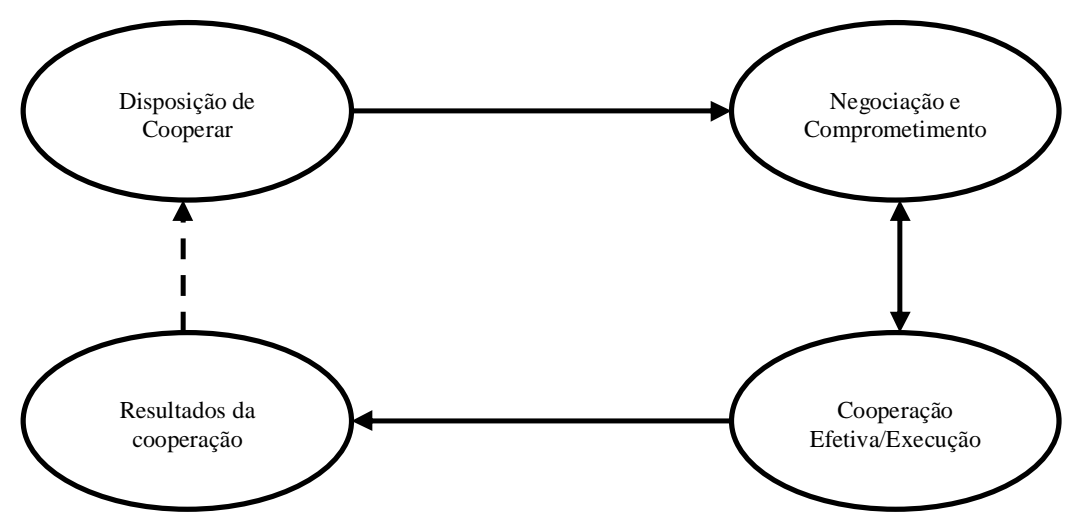

Fonte: elaborado com base em Sbragia (1994 como citado em Segatto, 1996, p. 11); Bonaccorsi e Piccaluga (1994 como citado em Segatto, 1996, p. 13) e Ring e Van de Ven (1994, p. 97).

O modelo apresenta as fases de desenvolvimento da cooperação que devem ser consideradas, para que se atinja o sucesso ou fracasso do acordo cooperativo. Neste âmbito, incluem-se, primeiramente, os motivos que levam as partes a estabelecerem a relação; posteriormente, a troca de informações entre os parceiros, com o intuito de se conhecerem melhor e se estabelecerem as principais diretrizes a serem seguidas durante o processo, bem como os contratos formais e informais; em seguida, leva-se em conta a realização da cooperação propriamente dita; e, por fim, estão os resultados da cooperação no que tange ao atingimento dos objetivos e satisfação das partes (Segatto, 1996).

Cabe ressaltar que a flecha de mão-dupla entre as etapas denominadas Negociação e Comprometimento e Cooperação Efetiva/Execução torna-se relevante, uma vez que, durante a execução do acordo, pode ser necessário um retorno às negociações com o estabelecimento de novas diretrizes e procedimentos a serem seguidos. Também convém estabelecer uma possível ligação entre as etapas denominadas Disposição de Cooperar e Resultados da Cooperação, dada a possibilidade de continuidade do acordo cooperativo entre a universidade e a empresa, após o término de um determinado projeto de cooperação.

Logo, conforme afirmam Guimarães e Plonski (2004, p. 2936), durante a realização da cooperação "interessa estabelecer um fluxo de conhecimento entre as instituições acadêmicas e de desenvolvimento tecnológico e os setores produtivos da sociedade", de forma que as tecnologias transferidas possam ser adequadamente apropriadas pelos parceiros, agregando valor às duas instituições e contribuindo para a ampliação de suas capacidades tecnológicas.

Dessa forma, espera-se que o estabelecimento de arranjos cooperativos, ou cooperação entre a indústria e a academia, proporcione benefícios para ambas as partes. No entanto, verifica-se, no âmbito desta relação, um desencontro de percepções, ou seja, universidade e empresa são regidas por valores próprios e distintos, com diferenciações em seus ciclos tempo, objetivos e motivações, de forma que a desconfiança entre eles existe e, muitas vezes, atrapalha a relação (Marcovitch, 1999). Desse modo, torna-se importante uma adequada infra-estrutura de comunicação, para que a transferência de tecnologia e, consequentemente, a cooperação tecnológica universidade-empresa obtenha sucesso. 


\section{COMUNICAÇÃO EM COOPERAÇõES TECNOLOGICAS UNIVERSIDADE-EMPRESA}

A comunicação é uma dimensão do processo organizacional que estrutura predominantemente as organizações (Littlejohn, 1982), sendo extremamente importante para o funcionamento de um ambiente organizacional (Almeida \& Hesketh, 1980). Para Marinho (2004), ela atua como fator estratégico, que deve ser planejado e controlado, de tal forma que possa gerar a transmissão adequada e oportuna de uma informação útil a um público específico.

No âmbito das relações interinstitucionais, Kunsch (1997, p. 69) afirma que "o sistema comunicacional é fundamental para o processamento ... do relacionamento das organizações com o meio externo". De forma complementar, Segatto-Mendes (2001) afirma que o estabelecimento de uma comunicação frequente e aberta entre os agentes envolvidos no acordo cooperativo universidadeempresa constitui componente de grande importância para o processo de transferência de tecnologia. Assim, para a coordenação do processo, Segatto (1996) alerta que é necessária a determinação de um código de comunicação comum a todos os participantes, permitindo, assim, que todos se entendam e compreendam as diversas etapas que estarão sendo elaboradas e executadas.

Diante disso, a análise da comunicação torna-se aspecto importante para o relacionamento cooperativo entre universidade e empresa, de forma que um sistema sólido de comunicação se torna fundamental para o estabelecimento de uma cooperação tecnológica bem-sucedida. Neste âmbito, a comunicação pode ser vista, conforme a metáfora do conduíte proposta por Putnam et al. (2004), como a transmissão de informações de uma fonte a um receptor, sendo a organização o canal por onde fluem estas informações.

Nos termos do estudo em questão, um processo de comunicação constitui um processo relacional entre duas organizações, caracterizado pelo encadeamento de ações contínuas e inter-relacionadas, na busca de um objetivo comum (Kunsch, 1997; Leite, 2006). Dentre os modelos de processo de comunicação apresentados na literatura, ressalta-se o modelo matemático de comunicação de Shannon e Weaver, no qual, conforme afirma Berlo (1999), a fonte de informação constitui a pessoa que fala; o transmissor, aquele que envia a mensagem da fonte; o sinal, o discurso a ser transmitido; o receptor, aquele que capta a mensagem para o destinatário; o destinatário, o ouvinte da mensagem; e os ruídos, fatores que distorcem a qualidade de um sinal.

Apesar do modelo de Shannon e Weaver apresentar como novidade, em relação a estruturas anteriores, a existência do componente ruído no processo de comunicação, em anos posteriores percebeu-se a necessidade de existência de outro aspecto de grande importância para o processo de comunicação: a retroalimentação, ou seja, um mecanismo que visasse assegurar o adequado recebimento da mensagem transmitida (Rogers, 1994; Wiener, 1968). Assim, na medida em que se considera a comunicação como processo, depara-se, segundo Berlo (1999), com relações dinâmicas e contínuas, nas quais os elementos constituintes se influenciam mutuamente. Desta forma, torna-se relevante considerar a retroalimentação como um dos componentes do processo de comunicação. Diante disso, sugere-se um modelo que incorpore esse componente e que pode ser esquematizado conforme a Figura 2. 
Figura 2: Modelo de Processo de Comunicação

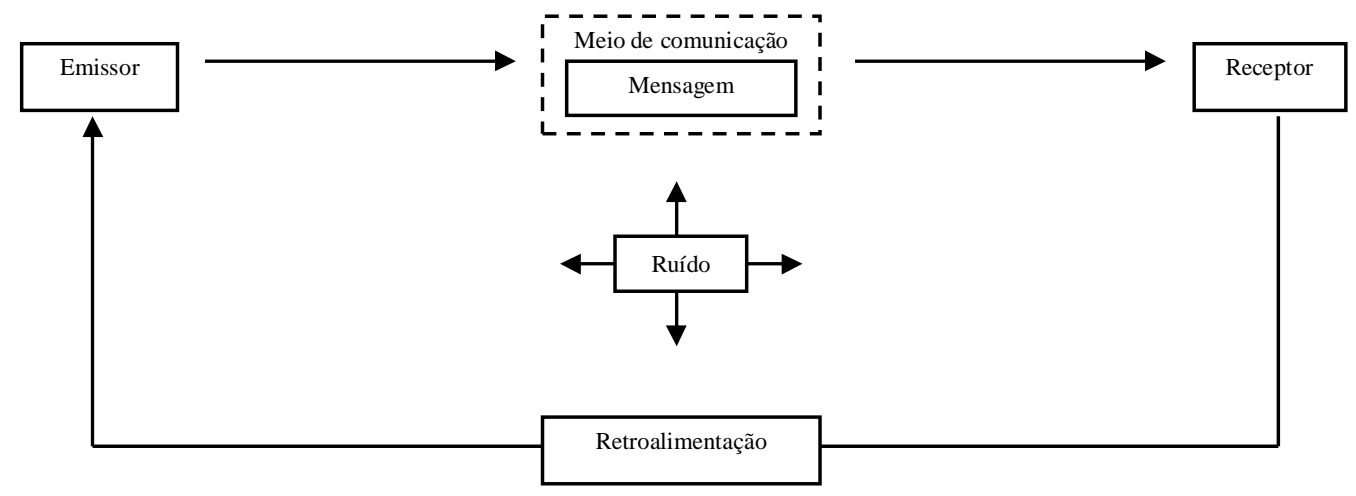

Fonte: adaptado de Shannon e Weaver (1949 como citado em Redfield, 1967, p. 6).

Diante deste modelo gráfico, considera-se um processo de comunicação como processo no qual um emissor, com o uso de um meio de comunicação, transmite uma mensagem a um receptor que, por sua vez, fornece uma resposta à fonte da mensagem, referente ao adequado recebimento da informação transmitida, cabendo ainda ressaltar a possível e provável existência de ruídos ao longo deste relacionamento.

O modelo de processo de comunicação proposto abrange, assim, os seguintes elementos de comunicação. (1) Os comunicadores: emissor - agente responsável por iniciar a comunicação com o propósito de emitir uma mensagem a uma ou mais pessoas - e receptor - pessoa(s) a quem se destina a mensagem (Senger \& Oliveira, 2003). (2) A mensagem: constitui, segundo Thayer (1972), a unidade básica da comunicação que é transmitida por um emissor e passível de aquisição por um receptor, podendo ter alguma importância, utilidade ou significado antecipado para o comportamento passado, presente ou futuro de quem a recebe. (3) O meio de comunicação: condutor da mensagem, ou seja, a forma física pela qual uma informação flui do pólo emissor para o pólo receptor (Kunsch, 1997). (4) A retroalimentação: corresponde, segundo Menezes (1973), ao retorno dado pelo receptor no que concerne ao recebimento e interpretação da mensagem. Por fim, (5) o ruído: constitui, na visão de Kunsch (1997), algum problema que interfere no processo, podendo dificultá-lo e até mesmo impedi-lo.

Enfim, a adoção de um código comum durante o processo de comunicação em acordos cooperativos representa um aspecto de fundamental importância para que os parceiros se entendam e consigam atingir os seus propósitos.

\section{Procedimentos Metodológicos}

O estudo classifica-se como descritivo-exploratório, pois visa descrever o fenômeno e explorar o assunto em questão, com o intuito de alcançar melhor compreensão do tema (Neuman, 1997). Consiste em uma pesquisa qualitativa, que fez uso do método de estudo de casos múltiplos como forma de atingir o objetivo proposto. Segundo Yin (2001), este método consiste na investigação empírica de um fenômeno, no âmbito de seu contexto da vida real, sendo preferível em relação ao estudo de caso único, em função dos benefícios analíticos que estes proporcionam.

Diante do tempo disponibilizado para a realização do estudo, bem como da proposta de trabalho apresentada, a pesquisa se enquadra na perspectiva temporal seccional ou transversal, já que os dados foram coletados em um período de tempo específico e único (Collis \& Hussey, 2005). No entanto, o 
estudo se aproximou da perspectiva longitudinal, uma vez que levantou informações ocorridas no passado (Richardson, 1999).

No que diz respeito ao nível de análise, este foi interorganizacional, uma vez que estudou processos de comunicação identificados ao longo de um relacionamento cooperativo. Por conseguinte, as unidades de análise foram universidades públicas do Paraná (Universidade Federal do Paraná [UFPR] e Universidade Tecnológica Federal do Paraná [UTFPR]) e empresas públicas/privadas que realizaram cooperações tecnológicas; no total três casos de acordos cooperativos. Por fim, o estudo apresentou, como unidade de observação, os processos de comunicação nas cooperações tecnológicas universidade-empresa analisadas. Os sujeitos da pesquisa foram os indivíduos envolvidos diretamente no processo, a saber: coordenadores dos projetos, estudantes-bolsistas de iniciação científica (graduação), mestrado e pós-doutorado, participantes dos projetos, pesquisadores e funcionários das empresas - também ligados à execução do acordo cooperativo.

Para a coleta dos dados o estudo optou pela aplicação de entrevistas semiestruturadas, observações diretas do fenômeno (reunião de projeto, visita a laboratório, visita à empresa e acompanhamento de atividades relacionadas aos projetos) e dados secundários (documentações e registros em arquivo), o que possibilitou posteriormente uma triangulação dos dados. Para o tratamento dos dados levantados pela entrevista foi realizada uma análise de conteúdo (Vergara, 2005), resultando em algumas conclusões relevantes do estudo.

Como complemento, destaca-se a confirmação de dados e a autorização dos envolvidos no que tange a publicação das informações coletadas ao longo da realização da pesquisa.

\section{DESCRIÇÃO DOS CASOS ESTUDADOS}

O estudo dos processos de comunicação, ao longo das fases de desenvolvimento da cooperação, envolveu três acordos cooperativos distintos: UFPR/PETROBRÁS (1 caso) e UTFPR/WEG ( 2 casos). $\mathrm{O}$ desenvolvimento de projetos de pesquisa conjunta aparece como característica das instituições citadas que visam, por meio desses acordos, a um maior aprimoramento de suas atividades e uma atuação com responsabilidade social, fato esse que se reflete no desenvolvimento econômico, social e tecnológico do país.

\section{Caso 1 - Cooperação UFPR e PETROBRÁS}

O primeiro caso em estudo envolve um Laboratório do Departamento de Geologia do Setor de Ciências da Terra da UFPR, e a empresa estatal PETROBRÁS. O laboratório é especializado em matéria-prima mineral e atua na área de caracterização química, mineralógica e física de minerais, rochas, solos e resíduos em geral, por meio de intenso contato com o setor produtivo, com quem desenvolve projetos de Pesquisa e Desenvolvimento [P\&D], em especial nas áreas ambiental e exploração mineral. A empresa, por sua vez, desenvolve atividades no setor petrolífero brasileiro, operando em diversas áreas do setor de energia, com destaque para exploração, produção, refino, abastecimento e distribuição de petróleo e gás natural.

O projeto, objeto de estudo da relação interinstitucional em pauta, compreendeu o desenvolvimento e a aplicação de uma metodologia para caracterizar Minerais Indicadores de Processos Termobáricos [MIPT], ligados a processos modificadores em rochas carbonáticas. O objetivo era caracterizar os processos diagenéticos e metamórficos que atuaram nas rochas carbonáticas, desde a sua deposição até a sua exposição atual, passando pelo soterramento e metamorfismo. Além do desenvolvimento da metodologia, procedeu-se à caracterização de zonas de carstificação, à elaboração de modelos geradores de porosidade, ao aprimoramento de metodologias analíticas para o estudo dessas rochas e ao fortalecimento das interações universidade-empresa. 
Quanto à abrangência da cooperação, universidade e empresa possuem uma visão um tanto quanto diversificada. Assim, para a academia o acordo foi considerado de atuação internacional, dada a participação de duas universidades americanas no desenvolvimento do projeto, representando uma abertura de portas para esse tipo de relação. $O$ projeto possibilitou, também, a participação da academia em congressos internacionais, fato característico, segundo a universidade, da abrangência internacional do projeto. Para a empresa, por sua vez, a cooperação envolveu apenas uma microrregião, dado o foco do estudo, que eram as rochas carbonáticas presentes no Paraná, e que a empresa utiliza para as bacias costeiras. No entanto, conforme afirma o coordenador do projeto, o fato de a empresa caracterizar a abrangência da cooperação como microrregional não impede que haja, futuramente, uma aplicação internacional do projeto.

A formalização do convênio foi feita por meio do estabelecimento de um termo de cooperação entre a universidade, representada por sua fundação (Fundação da Universidade Federal do Paraná [FUNPAR]), e a empresa. $\mathrm{O}$ acordo foi assinado na universidade, com a presença de testemunhas das duas partes acordadas, e envolveu a transação de recursos financeiros disponibilizados pela empresa à academia. Segundo o coordenador do projeto pelo lado da PETROBRÁS, verifica-se a existência de incentivo fiscal para a realização desse tipo de convênio.

No que diz respeito ao apoio de estruturas de interface, verificou-se, no estudo, a atuação da fundação no âmbito da universidade e do centro de pesquisas, pelo lado da empresa. A fundação, vinculada à academia, apóia na execução e no gerenciamento de programas e projetos de ensino, pesquisa - científica e tecnológica - e extensão, em diversas áreas de atuação. Assim, busca atender às necessidades da sociedade, por meio da colaboração, na prática de diversos projetos exigidos na universidade. Enfim, tem o intuito principal de facilitar a atuação da universidade no seu papel de utilidade pública e filantropia. O centro de pesquisas, por outro lado, constitui o laboratório de pesquisas da empresa, que atende às suas necessidades no que tange às atividades de Pesquisa e Desenvolvimento [P\&D] provenientes das demandas tecnológicas do mercado. Segundo o responsável pelo projeto no âmbito da empresa, o dentro representa um laboratório de extrema importância para a empresa, atuando como direcionador dos esforços desta com relação ao desenvolvimento de projetos de Pesquisa e Desenvolvimento [P\&D].

A periodicidade de interação dos dois agentes acontecia de três em três meses para a discussão do projeto em geral. No entanto, foram feitas também algumas reuniões fora desse período, para a resolução de assuntos técnicos pontuais, bem como algumas visitas ao campo. Todos os encontros eram registrados por meio de atas de reuniões, que ficavam armazenadas no laboratório.

Assim, a primeira fase de desenvolvimento do projeto, denominada Disposição de Cooperar, pode ser caracterizada, inicialmente, pelos motivos que levaram a empresa a buscar a universidade para o desenvolvimento do projeto, uma vez que a iniciativa partiu da empresa, e pelas motivações do laboratório em aceitar a participação no projeto. A fase de Negociação e Comprometimento compreende desde o primeiro contato ocorrido entre as partes, quando alguns geólogos da empresa foram ao laboratório para verificar o conhecimento do laboratório no estudo de rochas carbonáticas e o interesse deles para a realização do projeto, até a fase de assinatura do termo de cooperação. Os contatos posteriores, as primeiras visitas ao campo, o estabelecimento de procedimentos e diretrizes a serem seguidos ao longo do relacionamento, bem como os acordos informais firmados entre os agentes e a elaboração do plano de estudo também compreendem etapas dessa fase da cooperação. Em seguida, tem-se a fase conhecida como Cooperação Efetiva/Execução, na qual ocorre a execução do projeto propriamente dita. Nessa etapa, o contato entre o laboratório e a empresa passou a ser maior; houve visitas ao campo para coleta de amostras, treinamento de pessoal do laboratório na empresa, contato com profissionais especializados em rochas carbonáticas, principalmente em análises e interpretações das amostras obtidas. Por fim, foi possível enumerar os resultados provenientes do acordo, o que caracteriza a etapa de Resultados da Cooperação, na qual se verificou o interesse das partes em continuar com a parceria e o alcance dos objetivos previamente estabelecidos.

Além do alcance do objetivo principal, o projeto possibilitou inúmeros benefícios, tanto para a universidade quanto para a empresa. Por meio do acordo, a academia pôde colocar em prática o 
conhecimento que é passado aos alunos na teoria, além de conseguir financiamento para os estudos de Geologia; e pôde, enfim, desenvolver seu papel como promotora de ensino e pesquisa, aprofundando seus conhecimentos sobre o tipo de ambiente geológico envolvido pela pesquisa. A empresa, por sua vez, sofreu impactos positivos em seu pensamento estratégico, base de conhecimento, e na resolução de problemas na área de exploração de petróleo. Como complemento, foi possível verificar a realização de produções científicas, uma vez que, segundo o coordenador do laboratório, o projeto envolveu cerca de 4 ou 5 alunos bolsistas de graduação, 4 bolsistas de mestrado e 1 bolsista de pósdoutorado, a realização de projetos sociais e, até mesmo, a contratação, pela empresa, de uma pesquisadora do laboratório que atuou no projeto.

\section{Casos 2 e 3 - Cooperações UTFPR e WEG}

Os próximos dois casos estudados dizem respeito à cooperação entre o Laboratório de Vibrações [Lavib] da Universidade Tecnológica Federal do Paraná [UTFPR] e a WEG Equipamentos Elétricos, pertencente à WEG Indústrias Elétricas S/A. O Lavib pertence ao Departamento Acadêmico de Mecânica da UTFPR [DAMEC] e atua nas áreas de vibração, acústica e sinais, desempenhando atividades na linha de pesquisa de Controle de Vibrações, Dinâmica de Rotores, Caracterização Dinâmica de Materiais Viscoelásticos e Prognóstico de Dano. A WEG, por sua vez, é uma empresa nacional que atua nas áreas de comando e proteção, variação de velocidade, automação de processos industriais, geração e distribuição de energia, bem como na produção de tintas e vernizes industriais. Trata-se de uma empresa totalmente nacional, que possui mais de 20 mil colaboradores em todo o mundo. Ela investe bastante em novas tecnologias, desenvolvendo projetos que tragam maior modernização e competência para a empresa. Além dessas atividades de Pesquisa e Desenvolvimento [P\&D] ela também investe, com certa constância, em treinamento dos seus funcionários, como, por exemplo, apoio na realização de cursos de pós-graduação.

Diante do exposto, os dois casos em estudo envolveram o desenvolvimento de pesquisa conjunta entre uma universidade pública federal e uma empresa privada, constituindo, assim, um acordo bilateral. Ambos foram formalizados por meio da assinatura de um termo de cooperação entre a academia (representada pela fundação da universidade) e a empresa, com a transição de recursos financeiros do meio empresarial para o acadêmico e a existência de incentivo fiscal para a realização desse tipo de convênio. Por fim, não foi possível identificar uma periodicidade de interação formal dos agentes, sendo comum, ao longo do relacionamento, um contato maior do tipo professor-aluno.

\section{Caso 2 - 'Estudo Dinâmico de Rotores para Máquinas Elétricas Rotativas - Predição da Resposta Vibratória a Distintos Tipos de Excitações'}

Dada a existência de um projeto preestabelecido (um ano), o estudo foi descrito, quanto ao tempo, como de curta duração. No que concerne à abrangência, caracterizou-se como nacional, mas de influência internacional, pela universidade; e, como internacional, pela empresa, admitindo-se o repasse que, posteriormente, se esperava fazer dos resultados obtidos com o acordo.

O objetivo principal do projeto era desenvolver um modelo numérico para melhoria de produtos quanto a vibrações e ruídos, obtendo-se, a partir daí, um comportamento preciso da dinâmica do rotor. Para tanto o projeto foi elaborado em duas partes: (1) confecção do modelo numérico e protótipo experimental; e, (2) treinamento na área para o pessoal da empresa. Destaca-se que os objetivos continuaram os mesmos ao longo da cooperação e, à medida que o projeto evoluía, eram cada vez mais discutidos e aprofundados, em face do conhecimento que ambas as partes iam adquirindo ao longo do processo.

De forma complementar, verificou-se a transferência de recursos financeiros do meio empresarial para o acadêmico e a formalização do acordo, ocorrida por meio da assinatura de um termo de cooperação entre a academia (representada pela FUNTEF) e a empresa, termo de cooperação 01/2004. 
O apoio à pesquisa, por sua vez, pôde ser notado apenas do lado da universidade, com a atuação da FUNTEF, um órgão vinculado à academia, que gerencia os recursos obtidos por meio de acordos de cooperação entre a UTFPR e o meio empresarial. A FUNTEF consiste em uma fundação de apoio à educação, pesquisa e desenvolvimento científico e tecnológico e pertence à UTFPR. Por meio da fundação, a universidade coloca em prática suas atividades de ensino, pesquisa e extensão, contribuindo, dessa forma, para o estreitamento de suas relações com a comunidade e com a sociedade, de modo geral.

Quanto à periodicidade - formal - de interação, esta pode ser observada apenas no início do acordo, em função dos cursos que estavam sendo ministrados na empresa. Ao longo da execução do projeto propriamente dito, não ocorreram encontros formais frequentes entre as partes; todo o contato entre academia e empresa acontecia de maneira informal durante encontros diários.

A primeira fase do acordo entre a WEG e a UTFPR para a realização do projeto, assim, teve como característica principal a iniciativa da empresa, que já tinha conhecimento prévio do trabalho do professor responsável pelo laboratório de pesquisa. Diante disso, a empresa procurou a academia para o desenvolvimento de um projeto de cooperação conjunto, com vista à resolução de um problema encontrado por ela no decorrer de suas atividades diárias. A partir daí, teve início a etapa de Negociação e Comprometimento, caracterizada pela visita a empresa dos professores da UTFPR e da UFPR. O intuito principal era conhecer as suas necessidades, bem como discutir as bases iniciais de um projeto de pesquisa e a elaboração de um ciclo de cursos para o pessoal da empresa sobre o tema: controle de vibrações e dinâmica de rotores. Foram feitas algumas reuniões para discutir o projeto, o qual, depois de bem estruturado, possibilitou a assinatura do termo de cooperação. A próxima etapa, nomeada de Cooperação Efetiva/Execução caracterizou-se pela execução do estudo em si. A partir dela foi possível notar a presença de um contato maior entre universidade e empresa com o intuito de cumprir o objetivo proposto inicialmente. Foram também ministrados cursos na empresa sob o tema envolvido no projeto, de forma a capacitar seus funcionários quanto ao conhecimento teórico e prático na área de vibrações e dinâmica de rotores. Por fim, realizou-se a etapa de Resultados da Cooperação, a qual correspondeu ao alcance dos objetivos, em especial a elaboração do código numérico. Nos resultados alcançados transpareceu o interesse das partes em continuar com a parceria, fato que, entretanto, não pôde ser concretizado devido a alguns contratempos ocorridos nessa fase.

\section{Caso 3 - 'Estudo Dinâmico de Rotores para Máquinas Elétricas Rotativas - Parte II'}

O objetivo do projeto era aprofundar os conhecimentos adquiridos pelo primeiro projeto, com a realização de novas pesquisas, de melhorias no código numérico obtido anteriormente e de formação de pessoal especialista na área. Logo, o intuito era: (1) finalizar algumas atividades que tinham sido iniciadas no primeiro projeto; (2) desenvolver mais experimentos para validação do modelo obtido; (3) realizar novos desenvolvimentos teóricos; (4) fazer alterações, correções e adaptações no código numérico existente; e (5) propor e desenvolver atividades para obtenção de um modelo cada vez mais preciso. Cabe ressaltar a permanência dos mesmos objetivos, ao longo da cooperação, dada a clareza com que o projeto foi acordado e a cobrança natural que existia entre os parceiros.

No que diz respeito à abrangência, a cooperação pode ser caracterizada como internacional, pois a empresa parceira tem atuação no exterior e os resultados do projeto tiveram impacto estratégico para ela. Com relação ao tempo, ele representou um projeto de curta duração, por conter um plano de trabalho preestabelecido de dois anos. A formalização do relacionamento cooperativo entre a universidade - representada pela FUNTEF - e a empresa foi possível com a assinatura de um termo de cooperação entre as partes. Para a academia, o relacionamento com o meio empresarial foi caracterizado pela assinatura desse termo, que especificou o que cada parte iria fazer ao longo do projeto e a sua contribuição para que ele pudesse ser colocado em prática. Assim, como no projeto anterior, o apoio à pesquisa advinha da fundação da universidade, a FUNTEF, que tinha como função auxiliar a academia no alcance de seus objetivos de ensino, pesquisa e extensão. 
Por fim, a periodicidade de interação acontecia, na maioria das vezes, em encontros entre os coordenadores do projeto, por meio da relação aluno-professor, uma vez que o coordenador do projeto na WEG cursava mestrado na universidade. Esse contato ocorria a cada três meses, sem obrigatoriedade rígida, diante das necessidades percebidas durante a realização do acordo. Assim, como todos os projetos de desenvolvimento tecnológico que acontecem na empresa possuem cronograma, muitas vezes as etapas eram cumpridas com antecedência, não havendo necessidade de reuniões formais, uma vez que as informações necessárias já haviam sido trocadas. Dessa forma, verificou-se, nesse acordo, uma frequência maior de contatos informais.

Logo, a primeira fase de desenvolvimento da cooperação, Disposição de cooperar, partiu da proatividade de um funcionário da empresa, que entrou em contato com o coordenador do laboratório, a fim de verificar seu interesse na continuação dos estudos e de aprimorar ainda mais o modelo numérico existente. $\mathrm{Na}$ etapa seguinte, tiveram início as atividades de negociação e de comprometimento, caracterizadas por conversas, entre as partes, sobre as bases do novo projeto e a formalização do acordo de cooperação, respectivamente. A negociação, assim, teve como principal ponto de discussão o aspecto financeiro, o de investimento da empresa e, em função desse fator, as relações entre academia e empresa permaneceram estremecidas durante exatamente um ano. A execução da cooperação consistiu na realização das atividades, com o intuito de se atingir o objetivo proposto inicialmente. Assim, os esforços se concentraram basicamente no software que havia sido desenvolvido e que estava em fase de aperfeiçoamento. A etapa final de Resultados da Cooperação foi caracterizada por uma transformação do projeto que, depois de alguns meses em execução, foi colocado como contrapartida para um projeto FINEP. A partir daí, o projeto sofreu algumas modificações, possibilitando também a participação de outros professores da universidade.

\section{CARACTERIZAÇÃo dos Processos de ComunicaÇÃo}

Com relação ao primeiro caso de cooperação estudado, ocorrido entre a UFPR e a PETROBRÁS, de maneira geral, pode-se afirmar, no que tange ao interesse na comunicação, que tanto a universidade quanto a empresa atuaram como agente originador e receptor de mensagens, variando conforme a necessidade. Quanto à forma de comunicação, observa-se a existência de comunicações formais e informais; verbais e não-verbais; informativas, instrutoras e estimuladoras; rotineiras; intencionais e conscientes. No que tange aos objetivos, ao se comunicarem, universidade e empresa trocaram informações para desenvolver atividades não programadas, iniciar e estimular programas e atividades, fornecer dados necessários para tal, bem como trocar informações referentes aos resultados. Assim, o resultado alcançado com a troca de mensagens era algo inevitável, diante do respeito, comprometimento e elevada interação das partes. No entanto cabe destacar cada um dos elementos da comunicação, como forma de buscar um maior entendimento dos processos de comunicação no caso presente.

No segundo caso, denominado 'Estudo Dinâmico de Rotores para Máquinas Elétricas Rotativas Predição da Resposta Vibratória a Distintos Tipos de Excitações', os processos de comunicação identificados tinham como objetivos principais o início de programa, o fornecimento de dados necessários à execução de atividades ou o fornecimento de informações inerentes aos resultados do programa. As trocas de informações eram rotineiras e frequentes. Quanto ao interesse para o estabelecimento da cooperação, ambos os agentes se comunicavam com o intuito de atingir um objetivo em face da outra parte (originador) ou satisfazer uma necessidade por meio da mensagem recebida (receptor). Com relação à forma, verificaram-se, ao longo do acordo, processos de comunicação formais e informais, verbais e não-verbais, bem como informativos, instrutores e estimuladores. Logo, os processos de comunicação entre universidade e empresa ocorreram sempre de maneira consciente e intencional ao longo da cooperação, gerando resultados inevitáveis, uma vez que as necessidades e os interesses das partes eram compatíveis. 
O caso seguinte, 'Estudo Dinâmico de Rotores para Máquinas Elétricas Rotativas - Parte II', realizado novamente entre a UTFPR e a WEG, envolveu, por sua vez, processos de comunicação para atividades não programadas, início de programa, fornecimento de dados necessários para sua execução e, também fornecimento de informações referentes aos resultados do programa. Em cada etapa da cooperação foi possível caracterizar as mensagens trocadas ao longo do desenvolvimento do acordo, bem como os principais meios de comunicação utilizados, os possíveis ruídos e a existência de retorno, por parte dos receptores das mensagens. De forma geral, o interesse na comunicação envolveu tanto o atingimento de um objetivo por parte do receptor, como também a verificação de certa mensagem como necessária. Dessa forma, notou-se, durante o estudo, a existência de comunicação informativa, instrutora e estimuladora. Quanto à forma, foi possível identificar uma presença significativa de processos de comunicação informais e rotineiros, devido à amizade que existia entre os parceiros. A comunicação verbal e não verbal também esteve presente e ocorreu sempre de modo consciente, dada a existência de um projeto de pesquisa, ou seja, de diretrizes a serem seguidas. Logo, era elevada a frequência de comunicação entre as partes; isso possibilitou o sucesso inevitável do projeto, em razão, principalmente, do comprometimento e do respeito entre os agentes. A apresentação dos elementos constituintes dos processos de comunicação, em cada fase de desenvolvimento do acordo, tornou-se relevante para um entendimento maior da comunicação entre o LAVIB e a WEG.

Enfim, a caracterização dos processos de comunicação, identificados em cada uma das fases de desenvolvimento do acordo cooperativo nos três casos estudados, segue abaixo e é apresentado em forma de tabelas, com o intuito de facilitar a visualização dos processos. 


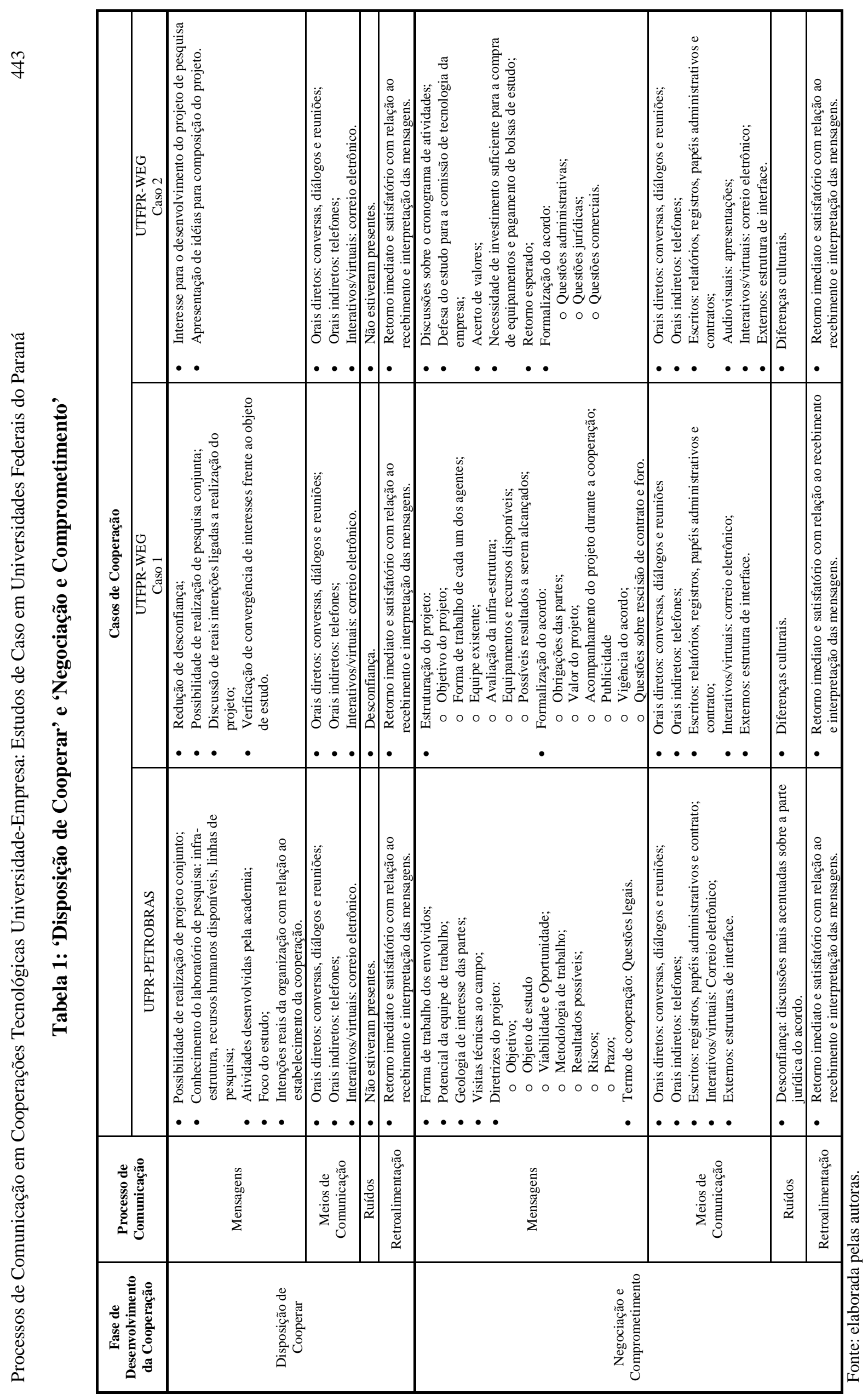

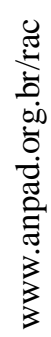

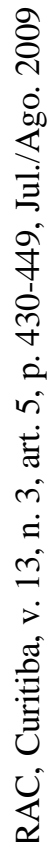




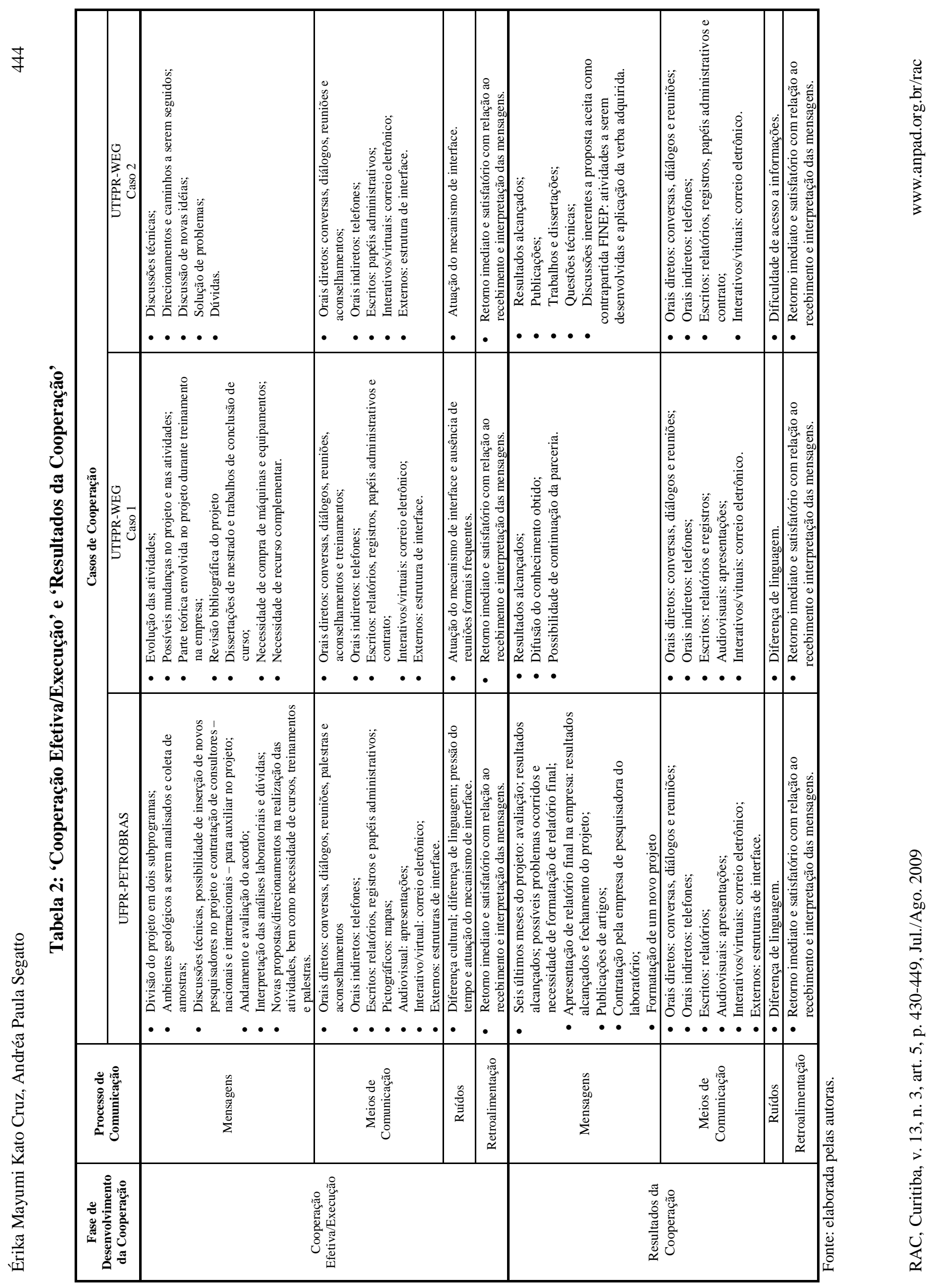




\section{CONCLUSÕES}

A análise da comunicação, em cada uma das fases supracitadas, permitiu levantar relevantes informações relativas às mensagens trocadas, aos meios de comunicação adotados, aos ruídos percebidos e à retroalimentação por parte dos receptores.

A conscientização dos parceiros quanto à relevância do estudo para ambos, a existência de comunicações rotineiras verbais e não-verbais, a verificação de objetivos comuns - início de programa, atividades não programadas, desenvolvimento das atividades e alcance de resultados durante a troca de mensagens, bem como a atuação das duas partes, em alguns momentos como originadoras das mensagens e, em outros, como receptoras, colaboraram para que o alcance dos resultados pretendidos com a comunicação fosse inevitável, refletindo também no sucesso dos acordos cooperativos estudados.

$\mathrm{Na}$ etapa inicial no projeto, Disposição de Cooperar, os parceiros trocaram informações, especialmente, sobre a possibilidade de realização de pesquisa conjunta, sendo observado, apenas na cooperação entre a UFPR e a PETROBRÁS, a necessidade de conhecimento do parceiro, bem como das atividades desenvolvidas por ele e de sua infra-estrutura para a realização do projeto. Os principais meios de comunicação utilizados nessa etapa foram: os orais diretos (conversas, diálogos, reuniões), os orais indiretos (telefonemas) e os interativos/virtuais (e-mails). No que tange aos ruídos, apenas a desconfiança por parte da empresa foi relatada em um dos casos estudados, fato este inerente, principalmente, ao tempo. Na medida em que a universidade precisa de um tempo maior para atingir suas metas, em função dos estudos necessários, deve existir nela a preocupação em demonstrar comprometimento e a posterior realização de um trabalho sério, de forma que a empresa possa adquirir maior confiança no trabalho da universidade e eles possam desenvolver um projeto conjunto.

A próxima etapa, denominada Negociação e Comprometimento, foi caracterizada pela troca de mensagens sobre estruturação do projeto e formalização do acordo. Aspectos ligados a objetivo, objeto de estudo, viabilidade e oportunidade, metodologia, resultados a serem alcançados, riscos, prazos e questões legais foram discutidos nesse momento. Quanto aos meios de comunicação, tiveram destaque os seguintes: orais diretos (conversas, diálogos, reuniões); orais indiretos (telefonemas); escritos (relatórios, contratos); interativos/virtuais (e-mails) e estruturas de interface. A atuação das fundações (estruturas de interface) nos acordos cooperativos estudados é obrigatória, uma vez que o termo de cooperação é firmado, tendo a fundação como representante legal da academia. Os ruídos identificados nessa fase dos processos de cooperação estudados abrangeram: (1) desconfiança das partes nas discussões ligadas ao comprometimento, principalmente com relação à segurança e à confidencialidade das informações trocadas; e (2) diferenças culturais, que interferiram, de alguma forma, na elaboração de plano de trabalho.

$\mathrm{Na}$ etapa de execução dos projetos, em que a comunicação costuma ser maior, as mensagens trocadas diziam respeito, principalmente, a questões técnicas e de andamento do projeto. Nesse sentido, foram discutidas questões sobre: (1) evolução das atividades; (2) resolução de problemas; (3) coleta, tratamento e análise de dados; (4) alteração de procedimentos; (5) novas idéias dentro do escopo do projeto; (6) participação de terceiros; (7) cursos, treinamentos e palestras necessários a uma maior capacitação das equipes; (8) solucionamento de dúvidas; (9) apresentações de relatórios; (10) revisões bibliográficas; e (11) compra de equipamentos e necessidade de novos recursos. Para tanto foi utilizado o maior número de meios de comunicação possível, a saber: meios orais diretos (conversas, diálogos, reuniões, aconselhamentos); orais indiretos (telefones); escritos (relatórios, papéis administrativos); pictográficos (mapas); audiovisuais (apresentações); interativos/virtuais (correio eletrônico); e externos (estruturas de interface). Nas cooperações, o ruído principal esteve atrelado à atuação da fundação durante o desenvolvimento do acordo. A crítica é direcionada especialmente à passividade do órgão, que apenas repassa os recursos utilizados e cobra dos pesquisadores a correta prestação de contas ao longo da execução do acordo, quando, na verdade, ele deveria atuar como instituição de apoio e gerenciamento de projetos e programas de ensino, pesquisa e extensão 
desenvolvidos pelas universidades. Outras interferências, como diferença cultural, diferença de linguagem, pressão do tempo e ausência de reuniões formais frequentes, também foram identificadas ao longo desta etapa.

Por fim, no que diz respeito ao alcance dos resultados provenientes dos acordos de cooperação analisados, observaram-se trocas de mensagens sobre o que segue: (1) objetivos alcançados; (2) avaliação geral do projeto e das atividades; (3) levantamento de problemas ocorridos; (4) formatação de relatórios finais, com informações de cunho fisicofinanceiro, técnico, gerencial e comercial; (5) publicações de artigos em congressos, encontros e revistas; (6) apresentações de trabalhos de conclusão de curso, dissertações de mestrado, teses de doutorado e trabalhos de pós-doutorado; (7) contratação de pessoal da academia pela empresa; (8) necessidade de continuação do projeto; (9) apresentação de idéias para novos projetos, dando continuidade aos estudos na área. Logo, para a troca das mensagens na etapa final do acordo foram utilizados estes meios de comunicação: orais diretos (conversas, diálogos e reuniões); indiretos (telefonemas); escritos (relatórios, registros, papéis administrativos, contratos); audiovisuais (apresentações); interativos/virtuais (correio eletrônico); e externos (estrutura de interface). Os ruídos principais dessa fase estiveram ligados às diferenças de linguagem e às dificuldades de acesso a informações, provocadas por atraso na assinatura de contrato inerente ao recebimento de apoio para pesquisa.

Enfim, ao longo das cooperações, foi possível notar trocas de mensagens específicas a cada fase do processo cooperativo, bem como uma variedade de meios de comunicação adequados às mensagens. Apesar da inserção das novas tecnologias de informação e comunicação, persiste nos acordos o uso de meios comunicativos convencionais: diálogos, reuniões, telefonemas. Por se tratar de casos de cooperação entre universidades públicas e empresas privadas, destaca-se a participação das estruturas de interface, no caso as fundações das universidades.

Logo, os acordos cooperativos trouxeram benefícios para ambas as partes; no entanto foi possível a identificação de ruídos ao longo desse processo, em especial àqueles relacionados à desconfiança, na etapa inicial do processo; diferenças culturais, na fase de negociação; e comprometimento, atuação dos mecanismos de interface, na etapa de cooperação efetiva; por fim, diferença de linguagem, no que tange ao alcance de resultados da cooperação.

Percebe-se ainda que, nos casos de cooperação estudados, a troca de informações proveniente dos meios informais de comunicação foi bastante frequente; o estabelecimento e o desenvolvimento do acordo criaram um clima de amizade e respeito entre as partes, que perdura até o presente momento.

Pode-se relatar, como complemento, a existência de retroalimentação, por parte do receptor, em todos os casos estudados. Ao longo das diversas etapas da cooperação, o retorno quanto ao adequado recebimento da mensagem, bem como possíveis questionamentos gerados, tanto da empresa, quanto da universidade, era sempre imediato. Todos os pontos envolvidos no decorrer das atividades eram discutidos e resolvidos rapidamente, de forma a cumprir com as metas propostas e satisfazer os parceiros. Assim, foram comuns, nos relacionamentos analisados, a satisfação das partes com relação ao acordo, de maneira geral, e o interesse em dar continuidade à parceria.

Desse modo, a pesquisa demonstrou que, ao longo das fases de desenvolvimento de um acordo cooperativo, é possível identificar diversos processos de comunicação que, juntos, descrevem a comunicação entre os parceiros no decorrer das atividades, podendo contribuir ou não para o alcance dos objetivos. Este estudo, que abrangeu três casos de acordos de cooperação distintos, possibilitou observar os tipos de mensagens que são transmitidas ao longo do relacionamento, os principais meios de comunicação utilizados pelas partes para a troca de informações, a existência de retroalimentação por parte do agente receptor da mensagem e, principalmente, a percepção de ruídos durante todas as fases de desenvolvimento da cooperação. A verificação de ruídos durante o processo cooperativo torna possível a discussão sobre formas de melhorar a comunicação entre as partes, com o intuito de estabelecer uma parceria mais saudável e benéfica para ambos os parceiros. 
De forma complementar, sugere-se, para estudos futuros, a aplicação dessa pesquisa em casos de cooperação estabelecidos em áreas de estudo semelhantes e também a realização de pesquisas com foco em outros aspectos e modelos de comunicação, como a questão do significado das mensagens nos processos comunicativos. Por fim, pelo fato de a presente pesquisa se caracterizar como estudo de caso (generalização analítica), seria interessante a sua utilização como base para estudos quantitativos na área, de modo a possibilitar uma generalização estatística dos dados coletados.

Artigo recebido em 27.02.2008. Aprovado em 01.09.2008.

\section{REFERENCIAS BIBLIOGRÁFICAS}

Almeida, M. A., \& Hesketh, J. L. (1980). Comunicação organizacional: teoria e pesquisa. Revista de Administração de Empresas, 20(4), 13-25.

Berlo, D. K. (1999). O processo da comunicação: introdução a teoria e a prática (J. A. Fontes, Trad.). São Paulo: Martins Fontes (Obra original publicada em 1970).

Castells, M. (2003). A era da informação: economia, sociedade e cultura. São Paulo: Paz e Terra.

Collis, J., \& Hussey, R. (2005). Pesquisa em administração: um guia prático para alunos de graduação e pós-graduação. Porto Alegre: Bookman.

Cunha, N. C. V., \& Fischman, A. A. (2003, outubro). Alternativas de ações estratégicas para promover a interação universidade-empresa através dos escritórios de transferência de tecnologia. Anales del Seminario Latinoiberoamericano de Gestión Tecnológica, Cidade do México, DF, México, 10 .

Guimarães, R. R. R., \& Plonski, G. A. (2004, outubro). Diferentes estratégias de instituições de P\&D públicas na cooperação com a indústria. Anais do Simpósio de Gestão da Inovação Tecnológica, Curitiba, PR, Brasil, 23.

Hall, R. H. (2004). Organizações: estruturas, processos e resultados. São Paulo: Prentice Hall.

Kunsch, M. M. K. (1997). Relações Públicas e modernidade: novos paradigmas na comunicação organizacional. São Paulo: Summus.

Leite, F. C. L. (2006). Gestão do conhecimento científico no contexto acadêmico: proposta de um modelo conceitual. Dissertação de mestrado, Universidade de Brasília, Brasília, DF, Brasil.

Lima, M. C., \& Teixeira, F. L. C. (2001). Inserção de um agente indutor na relação universidadeempresa. Revista de Administração Contemporânea, 5(2), 135-155.

Littlejohn, S. (1982). Fundamentos teóricos da comunicação humana. Rio de Janeiro: Zahar.

Marcovitch, J. A. (1999). A cooperação da universidade moderna com o setor empresarial. Revista de Administração, 34(4), 13-17.

Marinho, S. (2004, Octubre). Comunicação informal nas organizações: um estudo de caso em I\&D. Anales del Congreso Latinoamericano de Investigadores de la Comunicación, La Plata, Buenos Aires, Argentina, 7.

Menezes, E. D. B. (1973). Fundamentos sociológicos da comunicação. In A. Sá (Coord.). Fundamentos científicos da comunicação. Petrópolis: Vozes. 
Neuman, L. W. (1997). Social research methods: qualitative and quantitative approaches. Boston: Allyn \& Bacon.

Plonski, G. A. (1995). Cooperação empresa-universidade na Ibero-América: estágio atual e perspectivas. Revista de Administração, 30(2), 65-74.

Plonski, G. A. (1999). Cooperação universidade empresa: um desafio gerencial complexo. Revista de Administração, 34(4), 5-12.

Porto, G. S. (2002, novembro). O que discrimina a decisão empresarial de cooperar com a universidade. Anais do Simpósio de Gestão da Inovação Tecnológica, Salvador, BA, Brasil, 22.

Porto, G. S. (2004). Características do processo decisório na cooperação empresa-universidade. Revista de Administração Contemporânea, 8(3), 29-52.

Porto, G. S., Prado, F. O., \& Plonski, G. A. (2003, Octubre). As fontes de tecnologia no setor de telecomunicações e os fatores motivadores para cooperação. Anais do Seminário LatinoIberoamericano de Gestão Tecnológica, Cidade do México, DF, México, 10.

Putnam, L. L., Philips, N., \& Chapman, P. (2004). Métaforas da comunicação e da organização. In S. R. Clegg, C. Hardy, \& W. R. Nord (Orgs.). Handbook de estudos organizacionais (Vol. 3, Cap. 3, pp. 77-125). São Paulo: Atlas.

Redfield, C. E. (1967). Comunicações administrativas. Rio de Janeiro: FGV.

Richardson, R. J. (1999). Pesquisa social: métodos e técnicas. São Paulo: Atlas.

Ring, P. S., \& Van De Ven, A. H. (1994). Developmental processes of cooperative interorganizational relationships. The Academy of Management Review, 19(1), 90-118.

Rogers, E. M. (1994). A history of communication study: a biographical approach. New York: Free.

Segatto, A. P. (1996). Análise do processo de cooperação universidade-empresa: um estudo exploratório. Dissertação de mestrado, Universidade de São Paulo, São Paulo, SP, Brasil.

Segatto-Mendes, A. P. (2001). Teoria da agência aplicada à análise de relações entre os participantes dos processos de cooperação tecnológica universidade-empresa. Tese de doutorado, Universidade de São Paulo, São Paulo, SP, Brasil.

Segatto-Mendes, A. P., \& Sbragia, R. (2002). O processo de cooperação universidade-empresa em universidades brasileiras. Revista de Administração, 37(4), 58-71.

Senger, I., \& Oliveira, L. C. F. S. (2003). Comunicação organizacional: um meio de integração e envolvimento dos agentes nos ambientes organizacionais. Revista de Administração, 2(3), 111132.

Stal, E. (1998, novembro). Centros de pesquisa cooperativa e as motivações das empresas. Anais do Simpósio de Gestão da Inovação Tecnológica, São Paulo, SP, Brasil, 20.

Thayer, L. O. (1972). Princípios de comunicação na administração: comunicação e sistemas de comunicação na organização da administração e relações internas. São Paulo: Atlas.

Vasconcellos, E., Waack, R., \& Vasconcellos, L. (1997, setembro). Inovação e competitividade. Anais do Encontro Nacional da Associação Nacional de Pós-Graduação e Pesquisa em Administração, Rio das Pedras, RJ, Brasil, 21.

Vergara, S. C. (2005). Métodos de pesquisa em administração. São Paulo: Atlas. 
Processos de Comunicação em Cooperações Tecnológicas Universidade-Empresa: Estudos de Caso em Universidades Federais do Paraná

Wiener, N. (1968). Cibernética e sociedade: o uso humano de seres humanos. São Paulo: Cultrix.

Yin, R. K. (2001). Estudo de caso: planejamento e métodos. Porto Alegre: Bookman. 